\title{
Community Youth Radio in Rural Ireland
}

\author{
Jason P. Murphy ${ }^{1 *}$
}

(iD) 0000-0002-7905-0785

\section{Kate Bluett ${ }^{2}$}

(D) 0000-0002-7255-5107

\author{
${ }^{1}$ American University in Bulgaria, IRELAND \\ 2 Barnados, IRELAND \\ *Corresponding author: jmurphy@aubg.edu
}

Citation: Murphy, J. P., \& Bluett, K. (2021). Community Youth Radio in Rural Ireland. Online Journal of Communication and Media Technologies, 11(3), e202114. https://doi.org/10.30935/ojcmt/11105

\section{ARTICLE INFO}

Received: 15 May 2020

Accepted: 7 Jun 2021

\section{ABSTRACT}

This paper examines using media as a tool with which to engagement young people in in-formal education. It examines two approaches to youth radio and suggests pathways for future projects. The study took place at a community radio station in the West of Ireland, a geographically isolated rural region. The findings suggest that community radio can be a site of innovative, socially conscious media however this requires a strong product focus to audio texts.

Keywords: radio, community, youth, engagement, rural

\section{INTRODUCTION}

This study looks at two youth radio projects which took place concurrently at a community radio station in a rural location in the West of Ireland. The projects ran over a period of four months and took differing approaches to the practice of youth media. The two projects will be compared, and a model suggested for future youth radio projects as well as some limitations examined to both.

The two projects under review here differ in their structure. Both took place at the same community radio station in the West of Ireland during the Winter of 2012/2013. Group A were a group of five young people who were long standing volunteers at the station while group B were a new cohort. Group A received minimal input from station staff while Group B were mentored by a worker from local youth service and a station staff member. Here I will analyse the contrasting approaches, seek to identify strengths and weaknesses of both and referencing a call to examine the nature and form of facilitation (Santos et al, 2015) suggest a model that can be applied in other youth radio or audio settings.

\section{LITERATURE REVIEW}

Youth radio can be viewed as the radio branch of media education, itself understood to be a practice that whereby young people are trained to be producers of media, with the goal of them becoming more powerful participants in society (Buckingham, 2004). It's aims are broad including learning, community development, media literacy, technical and editorial skills, personal expression, critical thinking, aesthetic innovation, and social change (Soep \& Chavez, 2010), to these can be added; increasing local decision making by young people (Broadbent, 2010). Walker (2008) adds that a key purpose of youth media is to help young people develop a critical lens through which they can explore their identities, communities, and the media. More recent scholarship identifies the broader psychosocial benefits of youth radio in an on-line setting (Ravenscroft et al., 2018).

Youth radio is attractive from a youth development perspective for a number of key reasons. The first is that radio is a 'hands on' activity. There is a large number of technical skills to be acquired before one is

Copyright (c) 2021 by authors; licensee OJCMT. This article is an open access article distributed under the terms and conditions of the Creative Commons Attribution License (http://creativecommons.org/licenses/by/4.0/). 
proficient enough to be able to confidently broadcast or produce a piece, this technical aspect is innately appealing to many young people and the teaching of this allows an experiential style of learning from the outset. Secondly, using audio in this setting can make use of a range of skills. There is room for extroverts who want to be 'on air' but also for more introverted personality types who may prefer to be sound engineers or researchers or indeed themselves presenters. This is particularly useful from a group dynamic viewpoint. Thirdly, many young people are comfortable in front of a screen and in using software, which means that editing or other technical issues often do not faze young them, indeed many positively enjoy the technical aspect of the projects. Hopkins (2011) correctly identifies two processes at work in the development of nonformal learning opportunities around media production they are on the one hand using media as an area of interest with which to engage young people and on the other using the development of critical media skills as a key tool in empowering active citizens.

In the present study, the approach taken was informed by an experiential approach to learning with dialogue at its core (Dewey, 1910). This emphasis on dialogue has been shown to be at the center of a fruitful learning environment (Freire, 1970; Hooks, 1994). Within youth media work, Soep and Chavez (2005) developed the concept of a pedagogy of collegiality. This approach is grounded in the work of emancipatory education and, characterises "situations in which young people and adults jointly frame and carry out projects in a relationship marked by interdependence" (Soep \& Chavez, 2005). The approach is not one that is blind to institutional, historical and cultural forces that exist in any pedagogical relationship but through a focus on producing quality radio and media products, seeks to bind adult educators and young producers in a process that is progressive with an output that can reach a wider audience. This 'product' focus creates an environment where educators and participants co-create not only the learning environment but also the output. A key aspect to this pedagogy is that if conflict arises between product and process, the best interests of the young person are given priority. Campbell et al. (2001) characterise the balance between having young people participate and enjoy the experience and delivering on the goals of youth radio as a 'product versus process' dialogue. Curiously however this dialogue is absent from much of the literature. In 'process' orientated youth radio projects the emphasis is almost purely on participation with little if any regard paid to the audio texts produced (the product). This type of project is beneficial to participants in many of the same ways that 'product' orientated projects are, namely: teamwork, volunteering and technical skills. In a 2006 study Chan notes that the social part of creating media is more significant than what is produced or for whom, having fun and participating are the most important values (Chan, 2006). This model of being 'on-air' as a goal in itself is the most common expression of youth radio in Ireland.

Youth radio projects following a 'product' approach often seek to engage young learners with a method of learning that looks to recognise their various 'lifeworlds' (New London group, 1996) as central to the learning environment. Rather than assuming a uniform set of learners it instead looks to respect and acknowledge the individual multi-layered lifeworlds that individuals bring to an educational setting. This positioning seeks to incorporate the lived and imagined experience (Soep \& Chavez, 2005) of young people into the heart of the learning environment. This positioning is part of a longer tradition in critical education that encourages people to 'read their world' (Freire, 1970). Goodman (2003) combines his 'critical literacy' of analysis and decoding of media with a focus on production by young people of media texts that are based on concerns and issues in their lives (Goodman, 2003). The existing knowledge that young people bring to youth radio projects is not only recognised, it shapes the content of productions, ultimately leading towards a potentially transformed perspective that can then help to make sense of future experiences (Cope \& Kalantzis, 2000).

\section{METHODOLOGY}

This study looks at two approaches to youth radio employed at a community radio station in the West of Ireland. Group A followed what can be called a 'process' approach, one typified by high levels of participation and low support worker engagement. Group B followed a 'product' approach characterized by a focus on producing high quality audio texts with significant worker support.

An Action Orientated Media Pedagogy (AOMP) was used for Group B. Gunnel (2006) identifies AOMP as a way of planning a learning scheme that uses media production as the driver of learning. AOMP considers the social aspect of learning and looks at how learning happens through action. In it, the learning process is 
designed so that learners "actively and creatively consider how to deal with their social reality to work at solutions independently and communally" (Gunnell, 2006). AOMP identifies a number of outcomes that should follow from an effective youth radio program including; an extension of production, perception and reflection skills. The making of media products should be done in a reflective way with an emphasis on how they will be received by others, an extension of communication skills comes about not only through the process of scripting and production but also in negotiation with fellow members, these skills in turn should support and acquisition of self- confidence in different social situations, this growth in confidence comes from application of the previous skills and in particular from engaging with people outside of a person's usual circle. Of particular benefit are instances when participants are given opportunities to conduct interviews, allowing them to be in the position of holding control of an encounter and asking questions, this for young people can be a new experience. These outcomes correctly identify some of the key learning objectives of youth radio projects. AOMP explicitly calls for a product focus in its application. The overall architecture of Group B was an AOMP. This was combined with a pedagogy of collegiality approach.

\section{BACKGROUND TO THE AREA AND STATION}

Kilrush in Southwest Clare at first represents an unlikely site for a youth radio project. Located in the Shannon Estuary, in the far west of the country, Kilrush is a town with a population of 2,695 (2011 Census). The area is a historically impoverished region and continues to suffer from high levels of social exclusion. POBAL, the Irish government community development agency ranks the town as the fourth most disadvantaged community in the county (POBAL, 2011). At the time of this project, the Kilrush urban district had an unemployment rate of 37.8\% male, 23.0\% female (POBAL, 2011), within the communities served by this project the rates were significantly higher. The town has poor infrastructure, scant transport links and little in the way of public amenities or services. High unemployment and geographical remoteness are features along the entire West Coast of Ireland. Kilrush however suffers from problems more usually associated with larger cities especially high levels of drug abuse and associated problems.

Raidio Corca Baiscinn (RCB) is a community radio station located in the town of Kilkee, approximately 10 kilometers from Kilrush. It has been a fully licensed community radio station since 2008 . The radio station was setup as a community development project to "provide a local information, entertainment and training resource for the people of West Clare by the people of West Clare" (RCB, 2008). Mary Farren, its first chairperson, commented that "radio just happened, it could have been any project but we were determined to set up a community development project in West Clare" (Farren, interview 2014). In recognition of its community development focus, the station receives funding from the Irish Department of Social Protection through the POBAL scheme. RCB is part of the Community Services Programme (CSP) which supports community businesses to deliver local services to their communities and to employ people from disadvantaged groups.

\section{Group A}

Group A comprised three girls and a boy aged 15-16. This group of four young people all lived close by to the station and had a regular Friday night show. The show had been running for over a year before the start of this study period. The group were self-sufficient in terms of technical production and little 'hands on' support to broadcast. They had full editorial control of the content of their show. The culture that these young people grew up with at the radio station was one whereby turning up to do a show was a success in itself, there was little, if any attention paid to the content of each show by station staff. Frequently the group would arrive at the station ten minutes before going live and prepare the show during that time.

The content of shows produced by Group A were largely derivate of commercial radio and typically of poor quality. There were frequent technical errors and little attempt was made to consider an audience other than themselves. A typical thirty-minute program was complete with extended pauses, in-jokes and frequent outbursts of laughter. Examples of show content broadcast during the study was a top 10 list of funny YouTube videos, celebrity gossip and discussions of reality television programs. Music was played via their phones resulting in the broadcast of embedded YouTube advertising. 
While Group A produced poor content, the individuals involved group proved themselves to be excellent volunteers and contributed strongly to the lifeblood of the station. They made a consistent effort in fundraising activities and attended general meetings at the station, showing themselves to be committed to the station as a project.

\section{Group B}

Group B comprised seven adolescent girls, aged 12 to 14 years of age, who were already engaged in a local youth project. All participants lived in the same neighborhood, one that had been consistently identified as a socially disadvantaged area prompting the establishment of the youth project ten years previously. The project was the result of outreach by a worker from RCB. The youth project was being run by a local professional youth worker who was looking for new ways to engage the group. The structure of the project saw the Group and two support workers meet every week, alternating between the group's youth center In Kilrush and the RCB studios located in Kilkee.

The planning sessions took place in Kilrush. The aim of the planning session was to have a running order prepared for the following week's recording. This meant finding topics, writing intros and selecting music. The first planning task was the allocation of roles to each participant for the show being prepared. Roles included producer, presenter, and sound engineer. With seven participants, there were typically three presenters, two sound engineers, and two producers. There was often disagreement amongst participants about who should occupy which role. Allowing participants to resolve these disputes internally provided valuable learning for the participants' ability to resolve conflict and make decisions as a group.

Inspired by the work of Freire (1970) and others referenced in the literature review, the Group were encouraged to think of areas of interest that they could create content from. The role of support workers during planning sessions was to help shape topics by encouraging the group to reflect on their choices and by questioning, to draw out responses and challenge these. Prompting questions included What is important to you? What do you enjoy? What do you like about Kilrush? What would you change? These questions then formed the basis for group discussions and from those discussions the Group selected material for the show. This work was done in pairs and as they worked the facilitators moved around and spoke with all of the girls. At the end of these exercises the pairs presented their lists on an A3 sheet of paper and the other girls were encouraged to give feedback. Once this was complete, they democratically worked out which topics would be included in the running order and later recording session. Recording sessions were preceded by technical instruction from a staff member at RCB. The recording sessions were modeled on professional radio practice and included sound checks, printing of running orders, pre-loading music and a general professional approach.

Overtime Group B acquired more skills and crucially began to feel more comfortable in the studio environment. The support workers looked to increase the level of challenge. Both key workers felt that the group had potential to take on more challenging material and use a greater array of technical skills including vox-pops and telephone interviews. This decision carried the risk of removing ownership of the programme from the group and risk harming motivation. It also raised the question of how to expand topics while keeping the project interesting and relevant to this group. How this was done can be best illustrated by looking at a specific example.

Each episode contained a fashion feature that was researched, written and presented by a participant. It involved outlining what adolescent girls were wearing locally and which celebrities' fashion they were following. This feature ran for two shows without input from the facilitators and would not have been without benefits as it involved planning, scripting, and was presented by a member of the group who would have been one of the more reticent speakers. However, it was now clear that the participants were capable in producing features for radio, therefore the next challenge was to enable the participants to engage with the topics in a more critical and questioning way and to allow the participant's authentic opinions emerge. Yet it was clear that for the programme to remain youth-led, it was the participants who would need to take the idea and develop it.

As a starting point for this new idea, the facilitators used online resources including video and print media regarding the issue of ethical fashion and showed these to participants. One resource that particularly evoked 
a response was a video interview with an eleven-year-old girl who worked in a clothing factory. The interview initiated much conversation amongst participants regarding what they viewed as poor treatment of workers, including children their own age. The idea of incorporating this different ethical perspective to the fashion feature appealed to the group. It was suggested by the facilitators that given that the participants themselves had admittedly been previously unaware of this ethical issue, they may like to see if people in their local area were aware of this issue. In response to this suggestion, the participants then developed a short survey to be distributed at an upcoming youth festival they were due to attend. The survey asked respondents if they ever considered possible ethical implications when purchasing fashion wear and if they bought clothing from any companies who have been found to subject their staff to unfair and unhealthy conditions. The group surveyed both adolescents and adults face to face at the youth festival and the results were then corroborated with the help of the youth worker.

The research for the ethical fashion feature culminated in the group interviewing an established academic from an English university via telephone, a task which was challenging for the participants as they were used to talking with individuals from mainly their own rural community. Whilst the group required the assistance of the facilitators to source the interviewee and guide them in preparing their questions, the participants conducted the interview professionally and entirely on their own. This interview was recorded and subsequently broadcast as an item in their show.

This particular example of the fashion feature's development from a commercial replica to a wellresearched critique on a topic with an ethical slant reflected the evolution of the group and programme over the four-month period. It confirmed what the facilitators had believed from on the start; that the group had much potential, and that radio was an optimum medium through which to stimulate civic engagement, critical thinking, and expose the participants to ideas outside of their typical cultural sphere.

\section{DISCUSSION}

This study has looked at two approaches to youth radio projects, both with their advantages and shortcomings. Group A largely operated independently with editorial control. It was clear they enjoyed their involvement and contributed to the station in a variety of ways, displaying a strong volunteer ethos. From the point of view of the radio station they were model volunteers, they contributed positively while requiring little by way of resources. It was clear however that the group were capable of producing content with a greater social awareness but lacked the training to do so.

Group B operated under a partnership between the radio station and local youth services. It was a tightly managed project with modest resource requirements. The content produced was of a high quality with an audience appeal. In interviews and through observations it was clear the participants benefitted from the project in skill development and in broader psychosocial terms. However, after the project ended none of the participants from Group B continued as volunteers at the station.

A wide variety of studies have shown that youth radio projects are a potentially good site for youth development. In an Irish context, community radio stations would appear to be the ideal location for these projects, they have equipment, trained staff and many receive government support to carry out their community development work. In future youth radio projects perhaps, a blend of the two approaches outlined here would be desirable. Group B's engagement with the station ended when the support workers moved on. This was regrettable, while fixed length projects are a feature of youth work, community radio stations should be attempting to perform this type of outreach work as a matter of course. Partnerships at the local level between community stations and services for youth, older people or those with disabilities represent a potentially area for development.

Day (2009) identifies community radio in Ireland as a potential site of emancipatory media practice, but drew into question just how alternative or emancipatory the sector was. The input of support workers in Group B's editorial output could be seen as a way of creating higher quality audio texts. Ultimately, it is the experience of the individual participating in a youth media project which is priority. Future researchers may look to combine the strong volunteer ethos of Group A with the engaged pedagogical approach of Group B. Group A had essentially been exposed to a 'hands off' style from station management since their initial 
introduction to the station. It is our view that joining strong process and product approaches would yield benefits for participants and wider society through more improved audio texts.

Author contributions: All authors were involved in concept, design, collection of data, interpretation, writing, and critically revising the article. All authors approve final version of the article.

Funding: The authors received no financial support for the research and/or authorship of this article.

Declaration of interest: Authors declare no competing interest.

Data availability: Data generated or analysed during this study are available from the authors on request.

\section{REFERENCES}

Broadbent, R. P., \& Papadopoulos, T. (2010). 'We didn't even realize that kids like us could go on the radio' - an evaluation of a Victorian schools youth development programme. Journal of Youth Studies, 13(2), 235254. https://doi.org/10.1080/13676260903295075

Campbell, P. H., Hoey, L., Perlman, L. K. (2001). Sticking with my dreams: Defining and refining youth media in the 21st century.

Chan, C. (2006). Youth Voice? Whose Voice? Young people and Youth Media practice in Hong Kong. McGill Journal of Education, 41(3), 215-225.

Cope, B., \& Kalantzis, M. (2000). Multiliteracies. Literacy learning and the design of social futures. Routledge.

Day, R. (2009). Community radio in Ireland: Participation and multiflows of communication. Hampton Press.

Dewey, J. (1910). How we think. Heath and co. publishers. https://doi.org/10.1037/10903-000

Farren, M. (2014, July). Personal communication.

Freire, P. (1970). Pedagogy of the oppressed. Continuum.

Goodman, S. (2003). Teaching youth media: A critical guide to literacy, video production and social change. Teachers College Press.

Gunnel, T. (2006). From the margins to the cutting edge: In community media and empowerment. Hampton Press. Hooks, B. (1994). Teaching to transgress. Routledge.

Hopkins, L. (2011). Youth Worx: Increasing youth participation through media production. Journal of Sociology, 47(2), 181-197. https://doi.org/10.1177/1440783310386827

New London Group (1996). A pedagogy of multiliteracies: Designing social future. Harvard Education Review, 66(1), 60-92. https://doi.org/10.17763/haer.66.1.17370n67v22j160u

POBAL (2011). The 2011 Pobal HP deprivation index for small areas. Irish Government, Department of Rural and Community development.

Raidio Corca Baiscinn (RCB). (2008). Station Contract.

Ravenscroft, A., Dellow, J. M., Brites, M. J., Jorge, A., \& Catalão, D. (2020). RadioActive101-Learning through radio, learning for life: an international approach to the inclusion and non-formal learning of socially excluded young people. International Journal of Inclusive Education, 24(9), 997-1018. https://doi.org/10.1080/13603116.2018.1503739

Santos, S., Brites, M. J., Jorge, A., Catalão, D., \& Navio, C. (2015). Learning for life: A case study on the development of online community radio. Cuadernos.info, 36(36), 111-123. https://doi.org/10.7764/cdi.36.610

Soep, E., \& Chavez, V. (2005). Youth radio and the pedagogy of collegiality. Harvard Educational Review, 75(4), 409-434. https://doi.org/10.17763/haer.75.4.827u365446030386

Soep, E., \& Chavez, V. (2010). Drop that knowledge. University of California Press. https://doi.org/10.1525/9780520945456

Walker, D. (2008). Examining the intersections of popular culture \& youth radio after school. Youth Media Reporter, 2(1/6), 202-220.
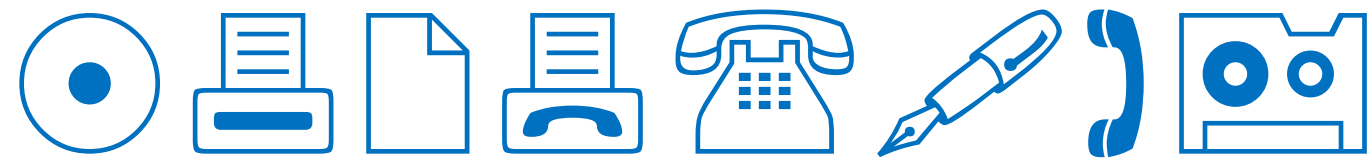